\title{
Effects of C/O Ratio and Temperature on Sooting Limits of Spherical Diffusion Flames
}

\author{
V.R. Lecoustre ${ }^{*}$ and P.B. Sunderland ${ }^{\dagger}$ \\ University of Maryland, College Park MD 20742 \\ B.H. Chao \\ University of Hawaii, Honolulu HI 96822, USA \\ D.L. Urban ${ }^{* *}$, D.P. Stocker ${ }^{\dagger \dagger}$ \\ NASA Glenn Research Center, Cleveland $\mathrm{OH} 44135$ \\ and \\ R.L. Axelbaum \\ Washington University, St. Louis MO 63130
}

\begin{abstract}
Limiting conditions for soot particle inception in spherical diffusion flames were investigated numerically. The flames were modeled using a one-dimensional, time accurate diffusion flame code with detailed chemistry and transport and an optically thick radiation model. Seventeen normal and inverse flames were considered, covering a wide range of stoichiometric mixture fraction, adiabatic flame temperature, residence time and scalar dissipation rate. These flames were previously observed to reach their sooting limits after $2 \mathrm{~s}$ of microgravity. Sooting-limit diffusion flames with scalar dissipation rate lower than $2 \mathrm{~s}^{-1}$ were found to have temperatures near $1400 \mathrm{~K}$ where $\mathrm{C} / \mathrm{O}=0.51$, whereas flames with greater scalar dissipation rate required increased temperatures. This finding was valid across a broad range of fuel and oxidizer compositions and convection directions.
\end{abstract}

\section{Nomenclature}

A area

$\mathrm{C} / \mathrm{O} \quad$ carbon to oxygen atom number ratio

$\mathrm{C} / \mathrm{O}_{\text {crit }}$ minimum $\mathrm{C} / \mathrm{O}$ for soot formation

$c_{p} \quad$ constant-pressure heat capacity of the gas mixture

$c_{p, k} \quad$ constant-pressure heat capacity of species $k$

$D \quad$ mixture-averaged diffusion coefficient

$h \quad$ specific enthalpy

$k \quad$ species number

$K \quad$ total number of species

$\dot{m} \quad$ mass flow rate

M molecular weight

$r \quad$ radius; oxygen/fuel mass ratio, Eq. (8)

$T \quad$ temperature

\footnotetext{
${ }^{*}$ Research Assistant, Department of Fire Protection Engineering.

$\dagger$ Assistant Professor, Department of Fire Protection Engineering, AIAA Senior Member.

*Associate Professor, Department of Mechanical Engineering.

${ }^{* *}$ Chief, Combustion and Reacting Systems Branch, AIAA Senior Member.

"Aerospace Engineer, Combustion and Reacting Systems Branch.

$\$$ Associate Professor, Department of Energy, Environmental and Chemical Engineering.
}

Paper AIAA-2008-827, January 7-10, 2008, Reno. 


$\begin{array}{ll}T_{f} & \text { peak temperature } \\ t_{r e s} & \text { residence time } \\ V_{k} & \text { diffusion velocity of species } k \\ V(r) & \text { velocity at radius } r \\ Y & \text { mass fraction } \\ Z & \text { mixture fraction } \\ Z_{s t} & \text { stoichiometric mixture fraction } \\ \lambda & \text { mixture thermal conductivity } \\ \rho & \text { gas density } \\ \chi & \text { scalar dissipation rate, Eq. (13) } \\ \dot{\omega} & \text { molar chemical production rate }\end{array}$

\section{Introduction}

Formation of soot in combustion is an active research topic. ${ }^{1-3}$ One fundamental measure of flame sooting $\boldsymbol{\Gamma}$ behavior is sooting limits. Sooting limits of spherical microgravity diffusion flames were observed by Sunderland et al. ${ }^{4}$ The present work is an investigation into those flames with the aid of a detailed computational model.

In the past, most data on fundamental sooting limits came from studies of laminar premixed flames. ${ }^{1,25-8}$. One reason for this is that both temperature and carbon-to-oxygen atom ratio, $\mathrm{C} / \mathrm{O}$, are nearly constant in the sootforming regions of premixed flames. Past studies found sooting limits in premixed flames to arise from a competition between fuel pyrolysis and oxidation of soot precursors. ${ }^{8}$ It was found that soot inception in premixed flames cannot occur when $\mathrm{C} / \mathrm{O}$ is below a critical value, about 0.6 for ethylene. ${ }^{1,2,5,7,8}$

A similar competition can occur in diffusion flames on the fuel side owing to the presence of oxygen in species such as $\mathrm{CO}_{2}$ and $\mathrm{H}_{2} \mathrm{O} .{ }^{4,9}$ Du et al. ${ }^{9}$ showed that adding $\mathrm{CO}_{2}$ to the fuel side of diffusion flames can suppress soot formation chemically. Despite the differences between soot inception in premixed and nonpremixed flames, the $\mathrm{C} / \mathrm{O}$ atom ratio has been shown to be relevant to sooting limits in diffusion flames. ${ }^{4,10}$ Past experimental work on spherical diffusion flames in microgravity identified a critical local $\mathrm{C} / \mathrm{O}$ value of 0.59 for ethylene. ${ }^{4}$

Temperature plays a different role in premixed and nonpremixed flames: increasing temperature suppresses soot formation in premixed flames, whereas it enhances soot formation in nonpremixed flames. ${ }^{2,8}$ Previous research on diffusion flames has identified an onset temperature at which soot particles are first observed to be in the range of $1250-1650 \mathrm{~K} .^{2,11-14}$

In addition to $\mathrm{C} / \mathrm{O}$ ratio and temperature, residence time (or scalar dissipation rate) is the third parameter critical to soot inception limits. Soot induction times of $0.8-15 \mathrm{~ms}$ were reported by Tesner and Shurupov in Ref. 15 for acetylene/nitrogen mixtures at $1473 \mathrm{~K}$. Strain rates of $30-200 \mathrm{~s}^{-1}$ were observed to prevent soot formation in counterflow diffusion flames. ${ }^{16,17}$

Microgravity allows the observation of strain-free diffusion flames. It also allows conditions with much longer residence times than can be obtained in normal gravity. These long residence times can yield new insights into soot inception limits, but they cause increased radiative losses that require consideration.

This study seeks to further investigate the effects of local $\mathrm{C} / \mathrm{O}$ atom ratio, local temperature, and residence time on sooting limits of spherical diffusion flames. The flames under consideration are the 17 microgravity flames of Ref. 4, having both normal and inverse convection directions and disparate stoichiometric mixture fraction, adiabatic temperature, and residence time. The model used here is a one-dimensional, time accurate diffusion flame code with detailed chemistry and transport and an optically thick radiation model.

\section{Numerical model}

The conservation equations were solved numerically using a flame code that includes detailed kinetics, based on GRI Mech 3.0 and involving 53 species and 325 reactions, and detailed transport properties. The numerical code was modified from the Sandia burner-stabilized PREMIX code, ${ }^{18}$ which was originally developed for the study of one-dimensional freely propagating and burner-stabilized premixed laminar flames. The code was adapted for spherical diffusion flames allowing for optically thick radiative heat losses. ${ }^{19}$ Both steady state and transient flames can be modeled.

Modifications were introduced to improve agreement with experimental results. Species and heat diffusivity has been increased by $30 \%$ from the original version. ${ }^{20}$ This increase yields higher peak temperatures and smaller flames.

In transient cases, the conservation of mass, energy, and gas species equations solved by the code are: 


$$
\begin{gathered}
A \frac{\partial \rho}{\partial t}+\frac{\partial \dot{m}}{\partial r}=0, \\
\rho A \frac{\partial T}{\partial t}+\dot{m} \frac{\partial T}{\partial r}-\frac{1}{c_{p}} \frac{\partial}{\partial r}\left(A \lambda \frac{\partial T}{\partial r}\right)+\frac{A}{c_{p}} \sum_{k=1}^{K}\left(\rho c_{p, k} Y_{k} V_{k} \frac{\partial T}{\partial r}+h_{k} \dot{\omega}_{k}\right)+R a=0, \text { and } \\
\rho A \frac{\partial Y_{k}}{\partial t}+\dot{m} \frac{\partial Y_{k}}{\partial r}+\frac{\partial}{\partial r}\left(A \rho Y_{k} V_{k}\right)-A M_{k} \dot{\omega}_{k}=0 \quad, \quad k=1,2, \ldots, K .
\end{gathered}
$$

The equations were solved subject to the following boundary conditions:

$$
\begin{gathered}
r=r_{b}: T=T_{b} ; Y_{k}=\frac{Y_{k, 0}}{1+\frac{\rho V_{k} A}{\dot{m}_{b}}} \quad, \quad k=1,2, \ldots, K \text { and } \\
r \rightarrow+\infty: T \rightarrow T_{\infty} ; Y_{k} \rightarrow Y_{k, \infty} \quad, \quad k=1,2, \ldots, K,
\end{gathered}
$$

where subscripts $b$ and $\infty$ refer to conditions at the burner surface and at the ambient, respectively. Variable $Y_{k, 0}$ is the mass fraction of the $k^{\text {th }}$ species in the burner gas supply. Because drop tower experiments did not show a significant increase in burner surface temperature, ${ }^{19} T_{b}$ was taken to be constant. The outer boundary temperature $(295 \mathrm{~K})$, species mass fractions, and pressure are held constant and specified as input data. However the velocity at the outer boundary is finite.

The computation requires a set of initial conditions that resemble the experimental ignition process. Following the approach adopted by Tse et al., ${ }^{21}$ the initial (ignition) conditions were prescribed as the steady-state solution of the same flame in a compressed domain. These ignition conditions had no radiation and assumed adiabatic conditions at the burner exit and a constant temperature at the outer boundary. The compressed domain was chosen to extend $1.2 \mathrm{~cm}$ from the burner center. The steady-state computations begin with a set of prescribed initial distributions of grid points, temperature, species concentrations, and an estimate of the location and thickness of the reaction region. After the steady-state solution is obtained, the grid is adapted to reduce the gradients and curvature and to improve accuracy. New grid points are added until all values of the gradients and curvature are below the user specified limits, and further addition of grid points does not affect the solution.

The steady state solution on the compressed domain is then used as the initial condition of the transient computations by expanding the domain of computation to $100 \mathrm{~cm}$ from the center of the burner, by adding grid points to fill the gap between the compressed and normal domains. All the computations used a grid of about 200 mesh points, finer in the area of high gradients (flame location), becoming coarser close to the outer boundary. Test cases were run to insure grid independence. Typically, about 120 extra mesh points were added from the compressed to the extended computation domain. The initial conditions at those extra mesh points were taken to be the user specified values for the outer boundary.

For the transient computation of the flame structure, radiative losses were considered. Radiation was considered optically thick and caused only by the participation of $\mathrm{CO}_{2}, \mathrm{H}_{2} \mathrm{O}$, and $\mathrm{CO}$. The radiative properties of these gases were formulated by a statistical narrow-band model with a spectral bandwidth of $25 \mathrm{~cm}^{-1}$. The emissivities were extracted from the line-by-line values given by the HITRAN database. ${ }^{24}$

\section{Experimental}

The tests considered here were performed and reported in Ref. 4. Further details of the apparatus are contained in Ref. 22. These experiments were conducted in microgravity in the NASA Glenn $2.2 \mathrm{~s}$ drop tower. The burner was a $6.4 \mathrm{~mm}$ diameter porous stainless steel sphere. All tests were conducted in quiescent ambient gas at $295 \mathrm{~K}$ and 0.98 bar and ignition was performed in microgravity. The tests employed three gases: ethylene, nitrogen, and oxygen. A color video camera was used to image the flames.

A summary of the 17 sooting limit flames is given in Table 1. Burner flow rates were selected such that all flames involved a steady-state ethylene consumption rate of $1.51 \mathrm{mg} / \mathrm{s}$ and a heat release rate of $71 \mathrm{~W}$, assuming complete combustion. Normal flames are realized when fuel discharges from the burner into an oxidizer atmosphere, while inverse flames are realized when oxidizer flows from the burner into an atmosphere of fuel. The fuel and oxygen mole fractions in the supply gases, $X_{C 2 H 4,0}$ and $X_{O 2,0}$, vary widely. This yielded a wide range of stoichiometric mixture fraction, $Z_{s t}$, as shown. Adiabatic flame temperatures were calculated using Chemical Equilibrium with Applications, CEA. ${ }^{23}$ 
Table 1. Summary of the sooting limit flames, reproduced from Ref. 4.

\begin{tabular}{cccccccc}
\hline Flame & Environment & $X_{\mathrm{C} 2 \mathrm{H} 4,0}$ & $X_{\mathrm{O} 2,0}$ & $Z_{s t}$ & $t_{r e s}, \mathrm{~s}$ & $T_{a d}, \mathrm{~K}$ & $T_{f}, \mathrm{~K}$ \\
\hline 1 & Oxidizer & 1 & 0.22 & 0.065 & 2.72 & 2390 & 1545 \\
2 & Oxidizer & 0.6 & 0.21 & 0.102 & 1.63 & 2326 & 1492 \\
3 & Oxidizer & 0.31 & 0.21 & 0.18 & 0.91 & 2226 & 1479 \\
4 & Oxidizer & 0.25 & 0.23 & 0.225 & 0.665 & 2238 & 1498 \\
5 & Oxidizer & 0.18 & 0.28 & 0.333 & 0.351 & 2306 & 1592 \\
6 & Oxidizer & 0.17 & 0.29 & 0.353 & 0.33 & 2308 & 1593 \\
7 & Oxidizer & 0.11 & 0.5 & 0.586 & 0.11 & 2381 & 1795 \\
8 & Oxidizer & 0.11 & 0.8 & 0.685 & 0.044 & 2528 & 2057 \\
9 & Oxidizer & 0.15 & 1 & 0.661 & 0.024 & 2740 & 2262 \\
\hline 10 & Fuel & 1 & 0.13 & 0.041 & 0.059 & 1847 & 1581 \\
11 & Fuel & 0.8 & 0.13 & 0.051 & 0.072 & 1835 & 1549 \\
12 & Fuel & 0.6 & 0.13 & 0.066 & 0.086 & 1814 & 1515 \\
13 & Fuel & 0.21 & 0.25 & 0.277 & 0.119 & 2274 & 1689 \\
14 & Fuel & 0.19 & 0.3 & 0.336 & 0.122 & 2370 & 1736 \\
15 & Fuel & 0.15 & 0.5 & 0.509 & 0.148 & 2539 & 1802 \\
16 & Fuel & 0.12 & 0.8 & 0.666 & 0.279 & 2578 & 1729 \\
17 & Fuel & 0.13 & 1 & 0.692 & 0.249 & 2670 & 1814 \\
\hline
\end{tabular}

Four representative flames at or near their sooting limits are shown in Fig. 1. These flames represent both convection toward oxidizer (normal flames) and convection toward fuel (inverse flames). The flames of Figures $1 \mathrm{~b}$

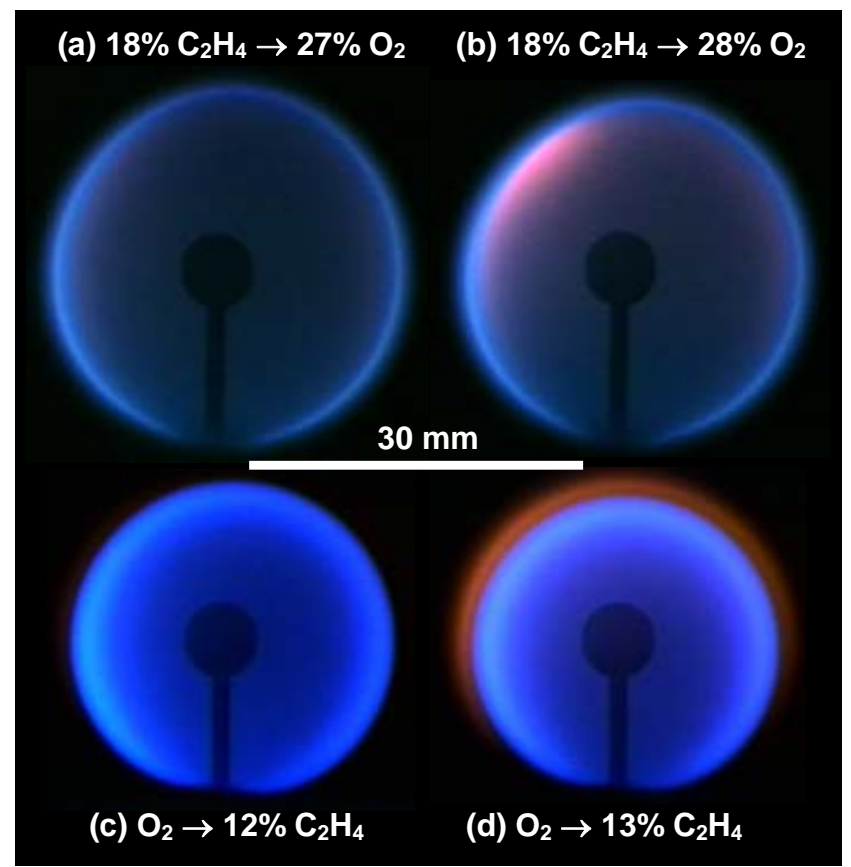

Figure 1. Color images of representatives flames below the sooting limits (a and $c)$ and at sooting limits (b and d) for convection toward oxidizer (a and $b$ ) and convection toward fuel (c and d). Flames (b) and (d) correspond to Flames 5 and 17 in Table 1. Images were taken just before drop termination and are reproduced from Ref. 4 . and $1 \mathrm{~d}$ are considered here to be at experimental sooting limits because a small reduction in reactant concentration yields blue conditions at drop end. Note that soot, when present, appears inside the flame sheet for normal flames and outside the flame sheet for inverse flames.

Flame temperatures $T_{f}$, taken as the peak temperature at $2 \mathrm{~s}$, are obtained from the numerical model. Residence time is the time for a parcel of gas to convect from the burner surface to the flame sheet. It is obtained by integrating the predicted flow field at $2 \mathrm{~s}$ :

$$
t_{\text {res }}=\int_{\text {burner }}^{\text {flame }} \frac{d r}{V(r)} \text {. }
$$

These residence times (see Table 1) are slightly different from the more approximate values obtained in Ref. 4 from a simple scaling analysis.

\section{Results}

The 17 spherical diffusion flames summarized in Table 1 were simulated using the modified PREMIX code. Predictions at $2 \mathrm{~s}$ after ignition were emphasized to better understand the conditions associated with the observed sooting limits. The flames modeled covered both normal and inverse configurations for a wide range of 


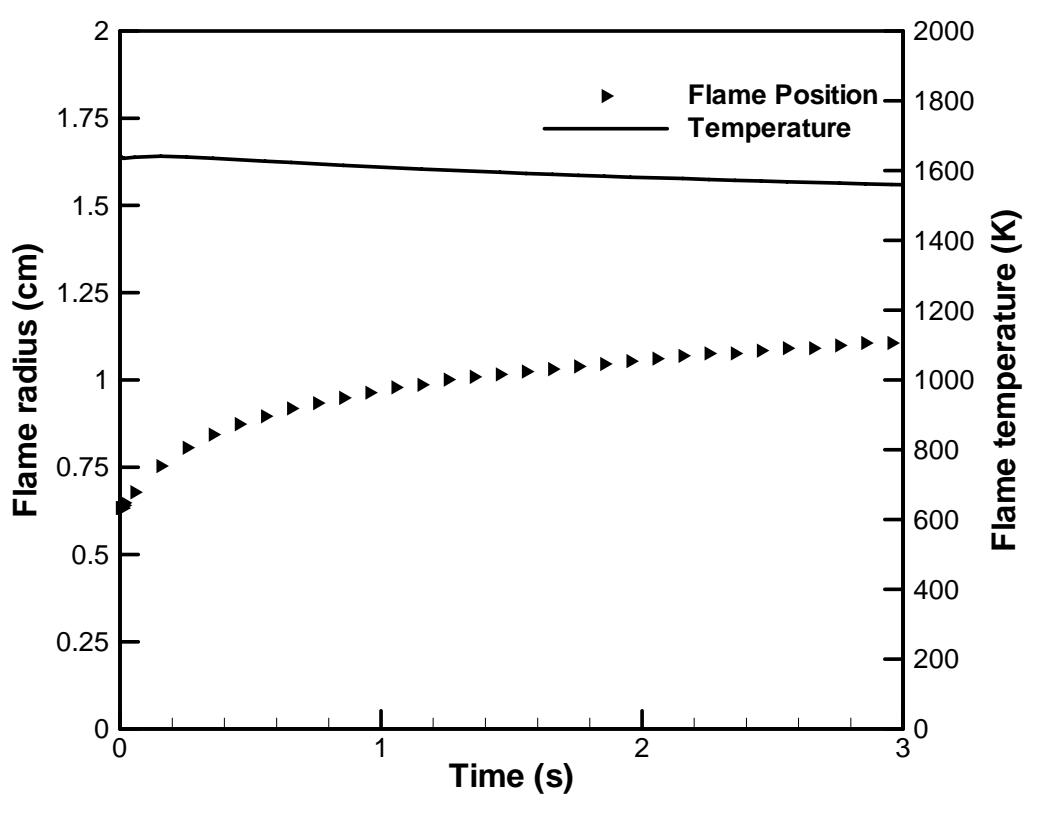

Figure 2. Predicted flame radius and peak temperature of Flame 10, from ignition ( $t=0 \mathrm{~s})$ to $3 \mathrm{~s}$.

residence time, $Z_{s t}$ and adiabatic flame temperature.

Figure 2 presents the Flame 10 computed flame radius and peak temperature evolution. Flame radius is defined as the peak temperature radius.

The proximity of the cold outer boundary in the compressed (ignition) domain promotes conductive heat losses, reducing the peak temperature below its adiabatic value. Immediately after ignition, the absence of conductive heat losses at the outer boundary increases slightly the flame temperature. The radius decreases slightly before increasing again.

The measurements and computations indicate that neither flame size nor peak temperature reaches steady state within $2 \mathrm{~s}$ for any of the present flames. Flame expansion causes temperatures to drop owing to increased radiative losses, which are proportional to flame surface area $^{19}$. At $2 \mathrm{~s}$, the radiative heat loss fractions are around 0.42 for all flames except Flames 10, 11 and 12, whose heat loss fractions are about 0.28 . Flame expansion is a critical aspect of all these flames.

A similar evolution occurs for flame temperature. For the flames of Table 1, peak flame temperatures at $2 \mathrm{~s}$ span a broad range of $1479-2262 \mathrm{~K}$. These temperatures are too high to cause radiative extinction at $2 \mathrm{~s} .{ }^{19}$

The calculation of mixture fraction, $Z$, for these flames is complicated by the presence of $\mathrm{N}_{2}$ in both the fuel and oxidizer in most cases. Furthermore, even for cases without fuel dilution, the conventional definition of $Z_{C H}=Y_{C}+Y_{H}$ does not yield peak temperatures at $Z_{s t}$. As discussed below, these complications can be overcome by including $Y_{\mathrm{O}}$ in the defined mixture fraction. ${ }^{25}$

A definition of $Z$, based on the mass fractions of $C, O$, and $H$ atoms, was derived by Bilger ${ }^{25}$ for methane. For any hydrocarbon fuel, $\mathrm{C}_{n} \mathrm{H}_{m}$, this becomes

$$
Z_{C H O}=\frac{Y_{C_{n} H_{m}}-Y_{C_{n} H_{m}, 2}+\frac{1}{r}\left(Y_{O_{2}, 2}-Y_{O_{2}}\right)}{Y_{C_{n} H_{m}, 1}-Y_{C_{n} H_{m}, 2}+\frac{1}{r}\left(Y_{O_{2}, 2}-Y_{O_{2}, 1}\right)},
$$

where 1 and 2 denote fuel and oxidizer supply, respectively, and where

$$
r=\frac{(n+m / 4) M_{O_{2}}}{M_{C_{n} H_{m}}} \text {. }
$$

One can express $Y_{C m H n}$ as a function of $Y_{C}$ and $Y_{H}$. This gives

$$
\left\{\begin{array}{l}
Y_{C}=\frac{n M_{C}}{M_{C_{n} H_{m}}} Y_{C_{n} H_{m}} \\
Y_{H}=\frac{n M_{H}}{M_{C_{n} H_{m}}} Y_{C_{n} H_{m}}
\end{array} \Rightarrow Y_{C_{n} H_{m}}=0.5 M_{C_{n} H_{m}}\left(\frac{Y_{H}}{n M_{H}}+\frac{Y_{C}}{m M_{C}}\right) .\right.
$$

For $\mathrm{O}_{2}$, we have the following relation:

$$
Y_{O_{2}}=\frac{M_{O_{2}}}{2 M_{O}} Y_{O}
$$

Inserting Eqs. (8 - 10) into Eq. (7) yields 


$$
Z_{C H O}=\frac{\frac{Y_{H}-Y_{H, 2}}{m M_{H}}+\frac{Y_{C}-Y_{C, 2}}{n M_{C}}+\frac{Y_{O, 2}-Y_{O}}{(n+m / 4) M_{O}}}{\frac{Y_{H, 1}-Y_{H, 2}}{m M_{H}}+\frac{Y_{C, 1}-Y_{C, 2}}{n M_{C}}+\frac{Y_{O, 2}-Y_{O, 1}}{(n+m / 4) M_{O}}},
$$

which, for ethylene, becomes:

$$
Z_{C H O}=\frac{\frac{Y_{H}-Y_{H, 2}}{4 M_{H}}+\frac{Y_{C}-Y_{C, 2}}{2 M_{C}}+\frac{Y_{O, 2}-Y_{O}}{3 M_{O}}}{\frac{Y_{H, 1}-Y_{H, 2}}{4 M_{H}}+\frac{Y_{C, 1}-Y_{C, 2}}{2 M_{C}}+\frac{Y_{O, 2}-Y_{O, 1}}{3 M_{O}}}
$$

Zhou and Mahalingam ${ }^{26}$ evaluated various definitions of $Z$ by plotting predicted temperature profiles with respect to mixture fraction. This approach is shown in Fig. 3 for Flame 10. Two definitions of $Z$ are considered, each yielding peak temperatures at different values of $Z$. The $Z_{\mathrm{CH}}$ definition results in peak temperatures on the rich side of the known $Z_{s t}$ of 0.041. In agreement with Ref. 26, the $Z_{\mathrm{CHO}}$ definition of Eq. (12) does not have this problem; it therefore is adopted for the results that follow.

Figure 4 depicts the predicted structure of Flame 10 at $2 \mathrm{~s}$ after ignition. The inverse configuration of this flame is evident in the increase of $\mathrm{C} / \mathrm{O}$ with increasing radius. The temperature field extends to a radius of $9 \mathrm{~cm}$ at time $2 \mathrm{~s}$. All 17 flames present higher temperature and species concentration gradients inside the flames than outside.

Past work ${ }^{4}$ proposed that with sufficiently long residence times, at its sooting limit each flame has a location where $\mathrm{C} / \mathrm{O}$ and $T$ reach critical values below which soot cannot form. The numerical model allows this hypothesis to be tested using the present flames, which were observed to reach sooting limits at $2 \mathrm{~s}$. Figure 4 reveals that for Flame 10 there is a location on the fuel side where $\mathrm{C} / \mathrm{O}$ is 0.51 and $T$ is about $1400 \mathrm{~K}$. (The selection of these critical values is explained below.) Similar behavior with respect to these critical values is observed in all the present flames that have sufficiently low scalar dissipation rates, as shown below.

Although spherical diffusion flames are strain-free, their scalar dissipation rates are nonzero. As with strain, scalar dissipation rate can dramatically affect soot inception. Scalar dissipation rate is defined here as

$$
\chi=2 D_{\mathrm{N} 2}(\mathrm{~d} Z / \mathrm{d} r)^{2} .
$$

The diffusivity coefficient used in Eq. (13) is the diffusivity of $\mathrm{N}_{2}$ into the multicomponent mixture at the local temperature. The choice was made because $\mathrm{N}_{2}$ concentrations are relatively high near the peak temperature locations for all 17 flames.

Temperature and $\mathrm{C} / \mathrm{O}$ ratio profiles, similar to those of Fig. 4, were prepared for each of the present flames.

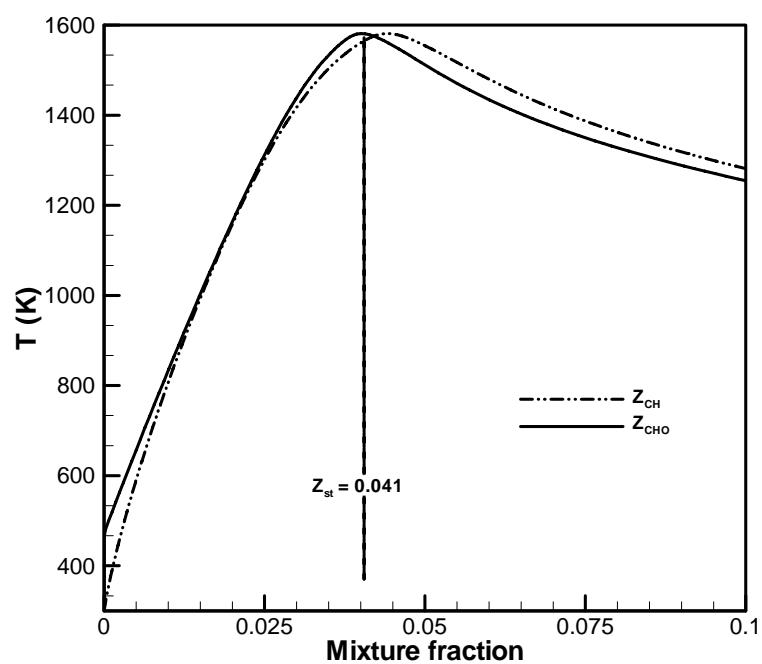

Figure 3. Predicted temperatures of Flame 10 plotted with respect to mixture fraction. Two definitions of mixture fraction are shown: $Z_{\mathrm{CH}}$ and $Z_{\mathrm{CHO}}$. Results are at $2 \mathrm{~s}$ after ignition.

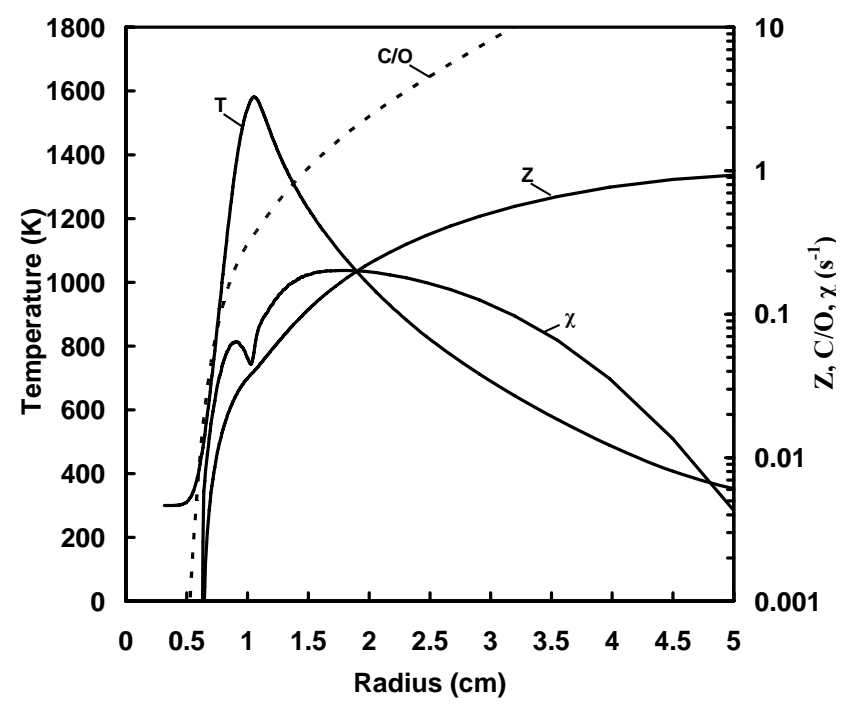

Figure 4. Predicted radial profiles of temperature, mixture fraction, scalar dissipation rate, and $\mathrm{C} / \mathrm{O}$ ratio for Flame 10. The burner surface is at $0.3175 \mathrm{~cm}$. Results are at $2 \mathrm{~s}$ after ignition.

6

American Institute of Aeronautics and Astronautics 
Various $\mathrm{C} / \mathrm{O}$ ratios near 0.6 were then considered. For each of these, the associated local temperature, $T(\mathrm{C} / \mathrm{O})$, and local scalar dissipation rate, $\chi(\mathrm{C} / \mathrm{O})$ were found for each flame. For each value of $\mathrm{C} / \mathrm{O}$, the standard deviation of these temperatures was considered. Flames $7-9$ had the highest $\chi(\mathrm{C} / \mathrm{O})$ and thus were excluded from the standard deviation calculations.

Figure 5 shows the relationship between the standard deviation of $T(\mathrm{C} / \mathrm{O})$ and $\mathrm{C} / \mathrm{O}$. The minimum occurs at a $\mathrm{C} / \mathrm{O}$ of 0.51 . The standard deviation is not strongly dependent on $\mathrm{C} / \mathrm{O}$ for $\mathrm{C} / \mathrm{O}$ in the range of $0.45-0.6$. Based on these results, the present flames indicate a critical $\mathrm{C} / \mathrm{O}$ ratio of $\mathrm{C} / \mathrm{O}_{\text {crit }}=0.51$. This is in reasonable agreement with previous reports of a value of 0.6 in ethylene premixed flames ${ }^{1,2,5,7,8}$, a value of 0.59 obtained in a simpler analysis of these spherical flames, ${ }^{4}$ and a value of 0.6 identified for gas-jet diffusion flames. ${ }^{27}$

Predicated on a value of $\mathrm{C} / \mathrm{O}_{\text {crit }}=0.51$, the associated local critical temperature, $T_{\text {crit }}$, and local scalar dissipation rate for each flame are shown in Figure 6 . The ordinate here is inverse scalar dissipation rate, which indicates a characteristic mixing time. The $T_{\text {crit }}$ values are similar for most of the present flames. The exceptions are Flames $7-$ 9 , which have the highest local scalar dissipation rates, i.e., $1 / \chi\left(\mathrm{C} / \mathrm{O}_{\text {crit }}\right)<0.5 \mathrm{~s}$, and thus require higher local

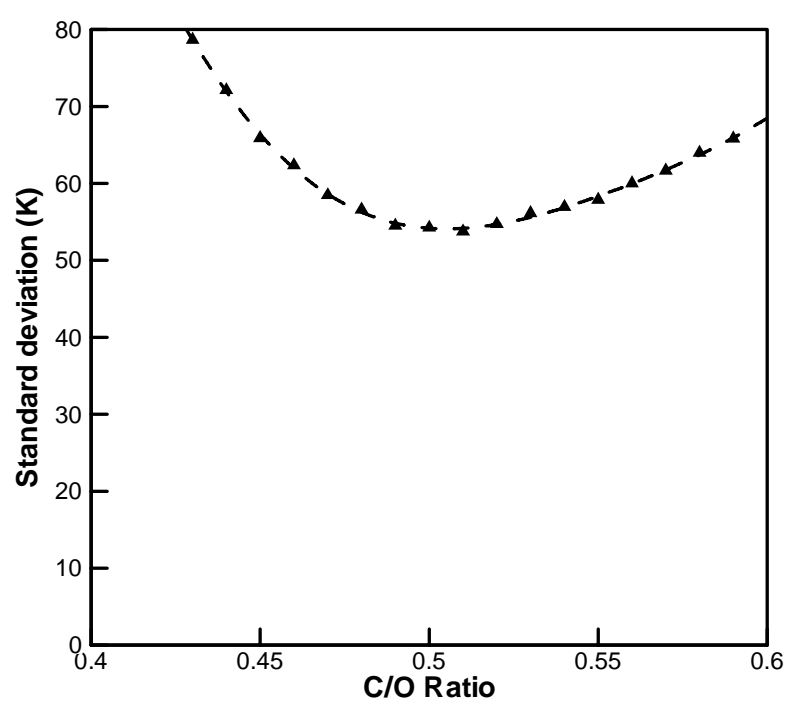

Figure 5. Standard deviation of $\mathrm{T}(\mathrm{C} / \mathrm{O})$ plotted with respect to $\mathrm{C} / \mathrm{O}$. Flames $7-9$ had the highest $\chi(\mathrm{C} / \mathrm{O})$ and thus were excluded.

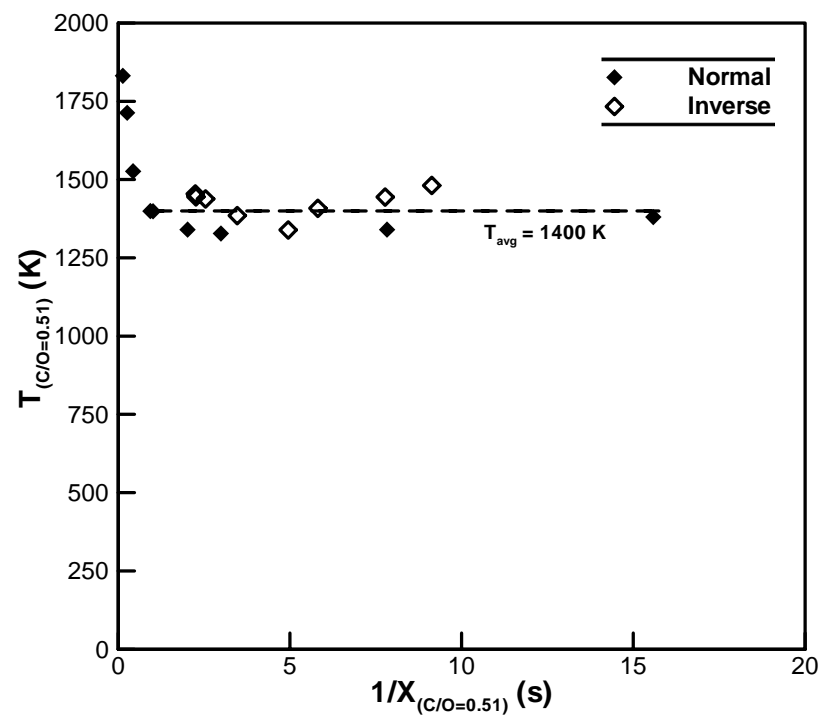

Figure 6. Predicted critical temperatures, at $\mathrm{C} / \mathrm{O}_{\text {crit }}=$ 0.51 , versus inverse scalar dissipation rate at this location for the present 17 flames. temperatures to reach their sooting limits. Excluding Flames $7-9$, the average $T_{\text {crit }}$ is $1400 \mathrm{~K}$.

The inverse of scalar dissipation rate gives an estimate of the characteristic mixing time. At the soot inception location, this time has a broad range, from $0.13 \mathrm{~s}$ (Flame 9) to $15.6 \mathrm{~s}$ (Flame 1). This characteristic time scales roughly with residence time for the normal flames and with inverse residence time for the inverse flames. Thus residence time is not a good indicator of scalar dissipation rate in spherical inverse flames.

Figure 7 shows the critical temperatures of Fig. 6 plotted with respect to $Z_{s t}$. The critical temperature for soot formation is seen to be independent of structure (represented by $Z_{s t}$ ) when Flames $7-9$ are excluded. These are identifiable as the three flames in Fig. 7 with the highest temperatures (and open symbols).

The present 17 sooting limit flames represent a broad range of conditions in terms of fuel and oxidizer supply concentrations, $Z_{s t}$, peak temperature, adiabatic flame temperature, convection direction, residence time, and scalar dissipation rate. Nevertheless, when

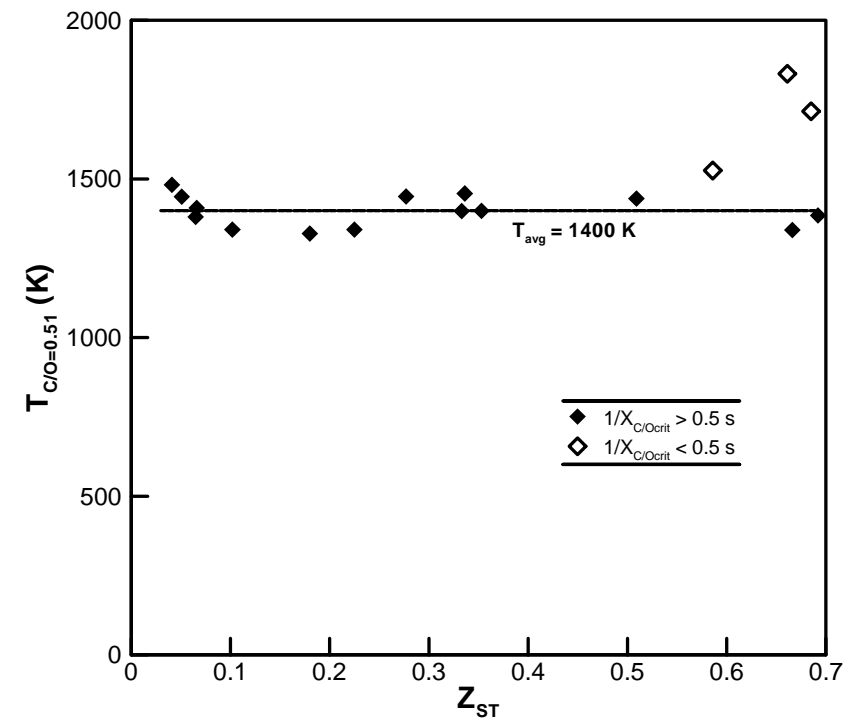

Figure 7. Predicted critical temperature, at $\mathrm{C} / \mathrm{O}_{\text {crit }}=$ 0.51 , versus $Z_{s t}$ for the present 17 flames. 
the three flames with the highest local scalar dissipation rate are excluded, a critical $\mathrm{C} / \mathrm{O}$ ratio of 0.51 , and a critical temperature of $1400 \mathrm{~K}$, occur at the sooting limits.

\section{Conclusions}

Computations with detailed chemistry and transport of spherical diffusion flames at sooting limits have been performed. Seventeen flames were considered, these having been previously observed to reach sooting limits after $2 \mathrm{~s}$ of microgravity. The key findings are as follows:

1) A mixture fraction calculated from local mass fractions of carbon and hydrogen atoms is not valid for these flames. An improved definition that also includes oxygen atom results in peak temperature near the stoichiometric mixture fraction.

2) Sooting-limit diffusion flames with sufficiently low scalar dissipation rate have similar temperatures where $C / O$ $=0.51$. For flames with scalar dissipation rate at this location lower than $2 \mathrm{~s}^{-1}$, these temperatures average $1400 \mathrm{~K}$ and are not affected by $Z_{s t}$.

3) Flames with scalar dissipation rate greater than $2 \mathrm{~s}^{-1}$ at this location require increased temperatures.

\section{Acknowledgments}

This work was supported by NASA Grants NCC3-696 and NAG3-1912 (BHC), NNC05-AA46A (PBS), and NCC3697 and NAG3-1910 (RLA).

\section{References}

${ }^{1}$ B.S. Haynes, H.G. Wagner, Soot formation, Prog. Energy Combust. Sci. 7 (1981), 229.

${ }^{2}$ I. Glassman, Soot formation in combustion processes, Proc. Combust. Inst., 22 (1988), 295.

${ }^{3}$ D.L. Urban, G.M. Faeth, Soot research in combustion science: introduction and review of current work, $39^{\text {th }}$ AIAA Meeting, January 8-11, Reno, NV, AIAA 2001-0332.

${ }^{4}$ P.B. Sunderland, D. L. Urban, D.P. Stocker, B.H. Chao, R.L. Axelbaum, Sooting limits of microgravity spherical diffusion flames in oxygen-enriched air and diluted fuel, Combust. Sci. Technol.,176 (2004), 2143-2164.

${ }^{5}$ M.M. Harris, G.B. King, N.M. Laurendeau, Influence of temperature and hydroxyl concentration on incipient soot formation in premixed flames, Combust. Flame, 64 (1986), 99.

${ }^{6} \mathrm{P}$. Markatou, H. Wang, M. Frenklach, A computational study of sooting limits in laminar premixed flames of ethane, ethylene and acetylene, Combust. Flame, 93 (1993), 467.

${ }^{7}$ F. Takahashi, Sooting correlations for premixed combustion. In Dryer, F.L. and Sawyer, R.F. (Eds.). Physical and Chemical Aspects of Combustion: A Tribute to Irvin Glassman, Gordon and Breach, Amsterdam 1997, pp. 161187.

${ }^{8}$ F. Takahashi, I. Glassman, Sooting correlations for premixed flames. Combust. Sci. Technol. 37 (1984), 1.

${ }^{9}$ D.X. Du, R.L. Axelbaum, C.K. Law, The influence of carbon dioxide and oxygen as additives on soot formation in diffusion flames, Proc. Combust. Inst., 23 (1990), 1501.

${ }^{10} \mathrm{~J}$. Du, R.L. Axelbaum, The effect of flame structure on soot-particle inception in diffusion flames, Combust. Flame, 100 (1995), 367.

${ }^{11}$ R.A. Dobbins, Soot inception temperature and the carbonization rate of precursor particles, Combust. Flame, 130 (2002), 204.

${ }^{12}$ I. Glassman, Sooting laminar diffusion flames: effect of dilution, additives, pressure, and microgravity, Proc. Combust. Inst., 27 (1998), 1589.

${ }^{13}$ R.J. Santoro, T.T. Yeh, J.J. Horvath, H.G. Semerjian, The transport and growth of soot particles in laminar diffusion flames, Combust. Sci. Technol., 53 (1987), 89.

${ }^{14}$ P.B. Sunderland, G.M. Faeth, Soot formation in hydrocarbon air laminar jet diffusion flames, Combust. Flame, 105 (1996), 132-146.

${ }^{15}$ P.A. Tesner, S.V. Shurupov, Soot formation from acetylene-benzene mixture, Combust. Sci. Technol., 92 (1993), 71.

${ }^{16}$ D.X. Du, R.L. Axelbaum, C.K. Law, Experiments on the sooting limits of aerodynamically-strained diffusion flames, Proc. Combust. Inst., 22 (1988), 387.

${ }^{17}$ K.-C. Lin, G.M. Faeth, Effects of hydrodynamics on soot formation in laminar opposed-jet diffusion flames, $J$. Propul. Power, 12 (1996), 691.

${ }^{18}$ R.J. Kee, J.F. Grear, M.D. Smooke, J.A. Miller, E. Meeks, A program for modeling steady, laminar, onedimensional premixed flames, Sandia National Laboratories Report No. SAND85-8240 1987. 
${ }^{19}$ K.J. Santa, B.H. Chao, P.B. Sunderland, D.L. Urban, D.P. Stocker, R.L. Axelbaum, Radiative extinction of gaseous spherical diffusion flames in microgravity, Combust. Flame 151 (2007) 665-675.

${ }^{20}$ K.J. Santa, Z. Sun, B.H. Chao, P.B. Sunderland, R.L. Axelbaum, D.L. Urban, D.P. Stocker, Numerical and experimental observations of spherical diffusion flames, Combust. Theory and Modelling, 11, 4 (2007), 639-652.

${ }^{21}$ S.D. Tse, D. Zhu, C.-J. Sung Y. Ju, C.K. Law, Microgravity burner generated spherical diffusion flames experiment and computation, Combust. Flame, 125 (2001), 1265-1278.

${ }^{22}$ Sunderland, P.B., Axelbaum, R.L., Urban, D.L., Chao, B.H., Liu, S., Effects of structure and hydrodynamics on the sooting behavior of spherical microgravity diffusion flames, Combust. Flame, 132 (2003), 25-33.

${ }^{23}$ B.J. McBride and S. Gordon, Computer Program for Calculation of Complex Chemical Equilibrium Compositions and Applications, NASA RP-1311-P2 (1996), Cleveland, OH.

${ }^{24}$ L.S. Rothman, C.P. Rinsland, A. Goldman, S.T. Massie, D.P. Edwards, J.-M. Flaud, A. Perrin, C. CamyPeyret, V. Dana, J.-Y. Mandin, J. Schroeder, A. Mccann, R.R. Gamache, R.B. Wattson, K. Yoshino, K.V. Chance, K.W. Jucks, L.R. Brown, V. Nemtchinov, P. Varanasi, J. Quant. Spectrosc. Radiat. Transf. 82 (2003) 5-44.

${ }^{25}$ R.W. Bilger, Structure of nonpremixed flames, Proc. Combust. Inst. 22 (1988) 475-488

${ }^{26} \mathrm{X}$. Zhou, S. Mahalingam, A suitable mixture fraction for diffusion flames of wood pyrolysis gas, Combust. Flame, 133 (2003) 197-199.

${ }^{27}$ B.M. Kumfer, S.A. Skeen, R. Chen, R.L. Axelbaum, Measurement and analysis of soot inception limits of oxygen-enriched coflow flames, Combust. Flame, 147 (2006) 233-242. 